\title{
Psychological Predictors of Cultural Diversity Support at Work
}

\author{
Annemarie M. F. Hiemstra \\ Erasmus University Rotterdam
}

Eva Derous

Ghent University

Marise Ph. Born

Erasmus University Rotterdam

Forthcoming in: Cultural Diversity and Ethnic Minority Psychology

(C) 2017 American Psychological Association. This paper is not the copy of record and may not exactly replicate the final, authoritative version of the article. Please do not copy or cite without authors permission. The final article will be available, upon publication, via its DOI: 10.1037/cdp0000141 


\begin{abstract}
Objectives: As diversity management activities become more prominent worldwide it is important to understand psychological reactions to them to ensure success, but empirical evidence is lacking. This study investigated employees and managers' intentions and behavior to promote cultural diversity at work in a variety of organizations in the Netherlands, using Ajzen's theory of planned behavior.
\end{abstract}

Methods: Predictors of intentions to promote cultural diversity at work $(N=670)$ and actual behavior after six months were assessed among managers and employees using self-reports in a two-wave survey design. Participant's average age at Time 1 was 38.26 years $(S D=11.86), 56 \%$ was female, and there were $78.1 \%$ Dutch ethnic majority and $21.9 \%$ ethnic minority participants. Results: Attitude to cultural diversity promotion at work and perceived behavioral control (PBC) related positively to both individuals' intentions to promote cultural diversity at work, which in turn predicted behavior. The strongest driver, however, was attitude. Managers' reported PBC and behavior were higher compared to employees.

Conclusions: This study supported the applicability of the theory of planned behavior to predict intentions and behavior to promote cultural diversity at work. With an increasingly diverse workforce, this study aimed to advance our understanding of drivers of individual reactions and behavior to support cultural diversity at work. 
DIVERSITY SUPPORT AT WORK

\section{Psychological Predictors of Cultural Diversity Support at Work}

In this era of globalization and international labor mobility, workforces in Western countries are culturally heterogeneous as never before (Hollifield, Martin, \& Orrenius, 2014). Cultural diversity and its consequences have therefore become an important issue in many Western organizations. Because organizations need to cope with this increasing diversity, a steady increase in attention for diversity management practices in organizations is noticeable. Cultural diversity management can be defined as a set of formalized practices implemented by organizations to effectively manage cultural diversity among all stakeholders with the intention to generate positive outcomes in the workplace (Olsen \& Martins, 2012). Cultural diversity management activities may focus on selecting for diversity, reducing workplace discrimination and creating financial competitiveness (Kossek \& Pichler, 2007). Recently, several multi-level theoretical models have been proposed on diversity management effectiveness in terms of work outcomes (e.g., Guillaume et al., 2014; Shore et al., 2009). In these multi-level theoretical models, societal, organizational, group and individual level factors were included. Empirical studies on actual support for cultural diversity management practices in organizations are rare, however. Furthermore, a better understanding of what gets people to actually act based on their psychological support is much needed. After all, following cultural diversity policies and actually showing diversity promotion related behaviors is a deliberate, conscious action that does not necessarily come naturally.

Support from both managers and employees is crucial when implementing cultural diversity policies and emipirical evidence on factors that affect their support and behaviors is limited. Our study aims to fill this gap in the literature by empirically studying psychological predictors of cultural diversity promotion intentions and behavior using Ajzen's Theory of 
Planned Behavior (2002). The theory of planned behavior identifies attitudes, social norms and perceived behavioral control as three predictors of intentions, which in turn should predict behavior. This theory has been successful in predicting behavior across a wide variety of domains, such as health related intentions and behaviors (Walsh, Hamilton, White, \& Hyde, 2015), job search behaviors (Schreurs, Derous, Van Hooft, Proost, \& De Witte, 2009), and organizational change readiness (Jimmieson, Peach, \& White, 2008). Furthermore, TPB has been successfully used to predict and/or explain pro-social behaviors, such as pro-environmental behaviors at work (Cordano \& Frieze, 2000; Greaves, Zibarras, \& Stride, 2013) and social justice behaviors in schools towards diversity in sexual orientations (McCabe \& Rubinson, 2008).

Despite these promising results, we are not aware of the application of TPB to study intentions and behaviors related to cultural diversity promotion. Two studies that come close, are the studies of Linnehan and colleagues (Linnehan, Chrobot-Mason, \& Konrad, 2006; Linnehan, Konrad, Reitman, Greenhalgh, \& London, 2003) who used the theory of reasoned action (TRA) to investigate predictors of diversity-related behaviors. According to the TRA, a precursor of the TPB, people's behavior is determined by their intention, and their intention is determined by their attitudes and subjective norms (Ajzen \& Fishbein, 1975). These two studies found support for the theory of reasoned action, but both of them used a cross-sectional design to predict actual behavior, thereby limiting the generalizability of findings. Other than these studies, we could not find any study that applied the theory of planned behavior to cultural diversity management in organizations. This is remarkable as there is an extensive body of literature on elements related to the TPB and their relation to diversity promotion. First, we review literature regarding our hypotheses on psychological antecedents of cultural diversity promotion and behavior. Next, a 
DIVERSITY SUPPORT AT WORK

short description is given of cultural diversity and diversity management in Western countries to illustrate the importance and urgency of the paper's study topic.

\section{Psychological predictors of workplace cultural diversity support}

Empirical studies on employees' psychological support for cultural diversity management and associated employee behaviors that stem from this support are rare. An exception is a series of US-based studies by Plaut, Garnett, Buffardi, and Sanchez-Burks (2011). They found that while cultural diversity policies that emphasize the value of diversity may be perceived positively by ethnic minority employees, such policies may actually receive low acceptance from ethnic majority employees. Following up on this finding, Jansen, Otten, and Van der Zee (2015) showed with a series of studies in the Netherlands, that a colorblind approach (i.e., cultural differences between employees are ignored and meritocratic values are emphasized) was most strongly related to work satisfaction for majority members, whereas a multicultural approach (i.e., cultural differences are explicitly valued) was perceived more positively by ethnic minority employees. Because managerial and employee support is crucial when implementing cultural diversity policies, and because empirical evidence on factors that affect managerial and employee support is so limited, we aimed to further our understanding by using the theory of planned behavior (TPB; Ajzen, 1991).

First, attitudes towards affirmative action have been studied extensively (Bell, Harrison, \& McLaughlin, 2000; Harrison, Kravitz, Mayer, Leslie, \& Lev-Arvey, 2006; Linnehan, et al., 2006; Linnehan et al., 2003). Affirmative action (e.g., creating equal opportunity in personnel selection) was introduced in the 1960's in the USA to combat employment discrimination and it is usually considered a subset of broader diversity management practices (e.g., hiring a diversity manager; see Harrison et al., 2006 for more information). Linnehan et al. (2003; 2006), for 
DIVERSITY SUPPORT AT WORK

instance, found that attitudes towards cultural diversity related behaviors were significantly related to intentions to engage in these behaviors (e.g., treating people with respect). Haley and Sidanius (2006) demonstrated that attitudes depend on how affirmative action is understood. They showed that individuals evaluated affirmative action more negatively when they perceived it as employing preferential treatment. Harrison et al. (2006) conducted a meta-analysis of studies on attitudes towards affirmative action and showed that the fairer a practice was perceived to be, the more positively it was evaluated. This meta-analysis also revealed that ethnic minorities were more positive than ethnic majority group members towards affirmative action.

Second, organizations are social structures and the perception of the social norms of significant others on diversity therefore can influence behavior. Empirical evidence suggests that employee diversity-related behavior is influenced by those in positions of authority (Brief, Dietz, Cohen, Pugh, \& Vaslow, 2000), who set the (social) norm in organizations. Indeed, Brief et al. showed that employees seem to be more prone to act on their bias through organizational justified reasons, such as the assumption that their superiors hold similar biases. Yet, climates that support diversity signal to organizational members that discrimination is inappropriate (Avery, 2011). Plaut, Thomas, and Goren (2009) showed that within the same organizational department White's multiculturalism positively predicted ethnic minorities' psychological engagement with their job and organization, whereas White's colorblindness negatively predicted ethnic minorities' engagement. Research has also shown that demographic differences are smaller for employee performance and absenteeism when the cultural diversity climate is perceived as more inclusive, which also suggests that social norms may affect support for diversity in organizations (Avery, McKay, Wilson, \& Tonidandel, 2007; McKay, Avery, \& Morris, 2009). A more direct test has been provided by Linnehan et al. (2006), who showed that 
DIVERSITY SUPPORT AT WORK

cultural diversity-related intentions were higher among public service employees when the social norm was perceived as more positive towards cultural diversity promotion behaviors (e.g., confronting those who engage in biased behavior at work or include members of demographic groups in work groups activities).

People who pose strong positive attitudes but do not engage in actual behavior might not do so because of the social norms as mentioned above, or because they do not perceive to have enough control over the performance. Lack of perceived behavioral control (PBC) may partly explain the gap between a positive attitude towards cultural diversity promotion and actual behavior related to cultural diversity promotion. $\mathrm{PBC}$ was added to the theory of reasoned action to better explain situations in which people may not have complete control over the behavior of interest (Ajzen, 2002). It has been argued that PBC consists of two related types of perceived control, namely self-efficacy and controllability (Trafimow, Sheeran, Conner, \& Finlay, 2002). Self-efficacy reflects the perceived difficulty of performing a behavior (Bandura, 1982) based on one's perceived personal characteristics (e.g., skills), whereas controllability refers to environmental constraints on behavior such as control over external resources (e.g., availability of resources, dependence of others; Ajzen, 1985). In this study only the controllability element of PBC was operationalized because decisions to actually implement cultural diversity-related interventions are usually not made by individual employees and may therefore be perceived by them as being beyond their personal control and self-efficacy beliefs. Instead, perceived behavioral control might depend on the job position one holds. Managers, for instance, are allocated more resources and are less dependent of others to make such influential decisions and are expected to have more control over organizational changes and interventions than other employees. Therefore, perceived behavioral control is expected to be stronger for managers than 
for employees. According to the TPB, perceived behavioral control in the form of controllability directly influences intention when it is considered a representation of actual control (Ajzen, 1991). Thus, the intention to engage in cultural diversity promotion activities should be stronger among managers than among employees. Taking attitude, subjective norm, PBC and management position into account, we proposed the following two hypotheses:

Hypothesis 1. Attitudes towards cultural diversity promotion, assessment of the subjective norm about cultural diversity issues, and perceived behavioral control in cultural diversity promotion will be positively related to intentions to engage in cultural diversity promotion activities at work.

Hypothesis 2. Managers will perceive higher behavioral control related to cultural diversity promotion and stronger intentions to engage in cultural diversity promotion activities at work than other employees.

Behavior. According to the theory of planned behavior (Ajzen, 1991), performance of behavior is a joint function of intentions and perceived behavioral control. Linnehan et al. (2003; 2006) identified several individual cultural diversity related behaviors in the United States. Among the identified behaviors assessed in a municipal organization by Linnehan and colleagues (2006) were confronting others when they engage in biased behavior, treating people with respect, better understanding of demographically diverse others, including members of wide variety of groups in discussions and activities, discussing issues of diversity, avoiding the use of offensive language and confronting others who use offensive language. The behaviors described the informal actions of individuals championing diversity. As mentioned, support was found for the TRA, although the cross-sectional design limits the generalizability of their findings. Additionally, contrary to informal actions of individuals 
DIVERSITY SUPPORT AT WORK

championing diversity, formalized cultural diversity management practices (e.g., awareness training) have the potential to penetrate across the organization more effectively (Yang \& Konrad, 2011). Behaviors aimed at influencing cultural diversity management practices may therefore be more effective for the organization as a whole, compared to more localized individual behaviors (like speaking up to those who use offensive language) as measured by Linnehan and colleagues (2006). Because we seek to understand the psychological underpinnings of cultural diversity management promotion behavior in this study, to better understand and ensure the success of diversity management policy interventions, we assessed behavior aimed at influencing the cultural diversity management in one's own organization across a variety of organizations and job positions.

According to the theory of planned behavior, one's behavior can be predicted by one's intention as well as by one's perceived behavioral control (Ajzen, 1991). A direct link between perceived behavioral control and behavior is probable because perceived behavioral control can be regarded as a substitute of actual control (Ajzen, 1991). When the intention is strong enough and the situational control over the behavior is sufficient, the desired behavior will be performed. In a formal power position, such as in management, actual control and perceived behavioral control is expected to coincide as management positions are generally defined to allocate accountability and responsibilities. Kellough and Naff (2004) stretch the importance of managers' commitment to the adoption and implementation of diversity policies. Furthermore, managers often act as a role-model when estimating appropriate behaviors within the organizational culture. Because much of the attention of employees is directed towards their manager, managers may have more opportunities to promote cultural diversity management when compared to individual employees. Therefore, we expected the following: 
Hypothesis 3. Intention to engage in cultural diversity promotion activities at work and perceived behavioral control in cultural diversity promotion will be positively related to actual behavior.

Hypothesis 4. Managers will engage in more cultural diversity promotion activities at work than employees.

\section{Importance of Cultural Diversity Management in Western Countries}

In many countries unemployment rates for ethnic minority groups are significantly higher compared to the majority group (OECD, 2013). For instance, in 2012 in the Netherlands, unemployment rates among lower educated ethnic minorities nearly tripled the unemployment rates for lower educated ethnic majority job seekers (20\% versus 7\%; Forum, 2012). Furthermore, migrants in many European countries are generally overrepresented in low skilled jobs despite relatively high levels of education. Their career progression to middle and high-skilled work severely lags behind when compared to native-born workers with similar educational attainments (Benton, Fratzke, \& Sumption, 2014).

Differences in majority and minority unemployment and career progression rates have been explained by various factors, such as socio-economic factors and minorities' lower levels of job competencies and work-related attitudes (e.g., Te Nijenhuis, De Jong, Evers, \& Van der Flier, 2004), but also to a substantial extent by hiring and workplace discrimination (Derous, Ryan, \& Nguyen, 2012; Dolfing \& Van Tubergen, 2005; Elliott \& Lindley, 2008). To stop workplace discrimination and to ensure cultural representation in various employment sectors, antidiscrimination laws and labor market policies have been introduced in different European countries (Benton et al., 2014; Kelly \& Dobbin, 1998; Kravitz, Harrison, Turner, Levine, Chaves, \& 
Brannick, 1997). Besides that, and depending on the political climate, employers are encouraged to increase diversity to enhance the potential of workers (Thomas, 1990).

In the USA, legislation to combat employment discrimination was introduced in the 1960s with the Civil Rights Act. With this legislation, employers were encouraged to take positive actions to end discrimination of disadvantaged groups (Kelly \& Dobbin, 1998), among which women and ethnic minorities. So-called 'affirmative action' is obligatory by US-law for federal and certain private organizations (e.g., federal contractors) to monitor their workforce statistics to help them ensure that the ethnic representation at work reflects ethnic proportions in society (Crosby, Iyer, Clayton, \& Downing, 2003).

Contrary to the USA, European societies were very ethnically homogeneous until the 1950s when many Western European countries started to promote labor immigration. In the Netherlands, for example, the largest groups that came to this country to work originated from Turkey and Morocco (Vervoort \& Dagevos, 2011). Because unemployment rates for minority groups in Europe are currently relatively high, the European Commission and other institutions increased their voice on immigrant issues. In 2000, this resulted in the Racial Equality Directive (2000/43/EC) against discrimination on grounds of ethnicity in employment, training, education, social protection, membership of organizations and access to goods and services (European Union, 2000). This directive obliged EU member states to introduce anti-discrimination laws (European Union, 2009). Moreover, various campaigns encouraged employers to adopt antidiscrimination practices (Sussmuth, 2007).

The empirical evidence for the effectiveness of diversity management policies is, far from convincing (Groeneveld \& Verbeek, 2012). An exception is a study by Kalev, Dobbin, and Kelly (2006) in which the effects of policies for managing diversity on the representation of 
DIVERSITY SUPPORT AT WORK

ethnic minorities in employment was studied in the United States. They showed that establishing structures of responsibility (such as responsibility for affirmative action plans) led to the largest increases in managerial cultural diversity in organizations. In another study, Hoque and Noon (2004) looked at the incidence of diversity policies in the United Kingdom and assessed whether these policies were substantial or merely 'window-dressing'. They suggested that for many organizations cultural diversity management policies have a symbolic function contributing to the organizations' legitimacy. These policies are not followed by actual, substantial activities. Policies that merely have a symbolic function or are only legislation driven (i.e., window dressing) will not have a direct impact on the representation of ethnic minorities in organizations (Groeneveld \& Verbeek, 2012). Support and commitment of senior management to actually implement diversity policies is considered an important condition for their success (Kellough \& Naff, 2004), but still open to further investigation.

Despite the introduction of equal employment measures and a growing understanding of diversity management at work, much remains unknown about the psychological underpinnings of employees' support for cultural diversity at work (Avery, 2011), especially outside the United States. Specifically, the study described here aimed at investigating employees' and managers' intentions and behavior to promote cultural diversity at work in a European context, namely the Netherlands, using Ajzen's (1991) theory of planned behavior (TPB). The proposed hypotheses were tested in a two-wave study among employees from a large variety of organizations in the Netherlands, as will be explained next.

\section{Method}

Participants and Procedure. Predictors of intentions to promote cultural diversity at work $\left(N_{\text {Time } 1}=670\right)$ and actual behavior after six months $\left(N_{\text {Time } 2}=172\right)$ were assessed among Dutch 
DIVERSITY SUPPORT AT WORK

managers/employees using a two-wave self-report survey design. Data were collected in cooperation with a large career magazine and a selection agency in the Netherlands. Sample characteristics at Time 1 are presented in Table 1. A cultural diversity policy was present in the organization according to $30.6 \%$ of the participants (Table 1). It was most often stated that targeted labor market communication (e.g., statements on website) was the main characteristic of their organizational cultural diversity policy (40.4\%). Other policy characteristics that were mentioned were: Coaching managers, coaching ethnic minority employees, composing ethnically diverse teams, hiring a diversity specialist, introducing culturally fair tests, and delivering intercultural communication training.

Those who responded at Time 1 were asked whether they agreed to be contacted again after six months $(50.45 \%$ agreed; $n=338)$. Those who agreed and left a valid e-mail address were invited again by e-mail six months after the Time 1 invitation had been sent. Two reminder e-mails were sent, one and three weeks after the initial Time 2 invitation. At Time 2172 questionnaires were filled out, resulting in a response rate of $50.9 \%$ among the 338 participants and $25.7 \%$ overall. The T2 sample included $76(44.2 \%)$ male and $96(55.8 \%)$ female participants. The mean age of T2 participants was 41.13 years $(S D=11.18)$. There were $82.7 \%$ ethnic majority group members, and $49.4 \%$ were classified as managers. Job position information was missing for 5 participants $(2.9 \%)$.

Measures. For the items of the cultural diversity promotion attitudes, subjective norms, perceived behavioral control, intention, and behavior scales (see below), a five-point Likert scale was used, varying from 1 = strongly disagree to 5 = strongly agree (i.e., Schreurs et al., 2009; Van Hooft, Born, Taris, \& Van der Flier, 2006). TPB items are presented in Appendix A. 
DIVERSITY SUPPORT AT WORK

Attitude is generally agreed to be a summary evaluation of a psychological object (cultural diversity support in our study) captured in attribute dimensions such as good-bad and likeabledislikeable (Ajzen, 2002). Research has underlined the centrality of attitudes related to cultural diversity promotion, such as attitudes towards affirmative action programs (Bell et al., 2000). Therefore, in the present study, attitude was measured with 3 items that asked to evaluate diversity behavior (good vs. bad, likeable vs. not likeable; useful vs. not useful), based on Ajzen (2002) and Bell et al. (2000).

The content of the cultural diversity policy was not further specified for two main reasons. Harrison et al. (2006) found that the effects of perceiver characteristics on attitudes towards affirmative action programs were stronger when concepts were presented in this generic way. They attributed this result to a tendency for respondents to construe an undefined statement on affirmative action in a manner consistent with their pre-existing schemas of affirmative action (Nacoste, 1994). Haley and Sidanius (2006) found similar results, showing that people tend to frame affirmative action in ways that are consistent with their beliefs: A negative belief resulted in framing affirmative action in ways that are generally more opposed, such as quota or preferential treatment. A positive belief resulted in the framing of affirmative action in ways that are generally less opposed, such as training or outreach. Finally, another important reason why cultural diversity policy measures were formulated in general terms was because research participants worked in very diverse organizations, branches and job positions. Hence, it was from both a theoretical and practical perspective not recommendable nor feasible to target specific diversity policies in the survey. The alpha for the attitude measure was high $(\alpha=.90)$.

Subjective norms are constituted by normative beliefs. Normative beliefs focus on the likelihood that important referent individuals or groups approve of performing certain behaviors 
(Ajzen, 1991). Subjective norms related to cultural diversity promotion behaviors were based on previous research (Cordano \& Frieze, 2000; Schreurs et al., 2009). The measure consisted of three items assessing how strongly significant others in the organization would approve of cultural diversity promotion. It was left to the respondents to decide what people they refer to as important in their organization (see also Schreurs et al., 2009, for this approach). The alpha of the subjective norms measure was .92 .

Perceived behavioral control within the theory of planned behavior deals with the presence or absence of necessary resources and opportunities. The perception of the availability of these resources and opportunities are control beliefs. The higher the control beliefs (i.e., the availability of resources and opportunities), the higher the perceived behavioral control (PBC) should be (Ajzen, 1991). Based on previous research items were developed for this study to measure PBC (3 items; Ajzen, 2002; Cordano \& Frieze, 2000). The reliability of this scale was .92.

Intention to perform a given behavior is a central factor in the theory of planned behavior (Ajzen, 1991). The items were based on previous research on TPB in work settings (3 items; Cordano \& Frieze, 2000; Van Hooft et al., 2006). Participants were asked to state their level of agreement to items about their intention to engage in cultural diversity management promotion behaviors. Especially one's job position could influence the authorization to make actual changes at a diversity policy level, with employees having less authority to do so compared to managers. To accommodate the broad organizational scope of our study, the format of the intention items was adapted (see Cordano \& Frieze, 2000): Instead of asking what participants intended to do, they were asked what they wanted to do. The reliability was .92 . 
Behavior was assessed at Time 2, six months after participants had filled out the first survey. Participants were asked about their actual cultural diversity promotion behavior in the last six months. Actual behavior was assessed with three items similar to the items of cultural diversity management promotion intention. The reliability of the behavior measure was .93 .

\section{Results}

\section{Descriptives and preliminary analyses}

The means, inter correlations and reliabilities of the study measures are presented in Table $2 \mathrm{a}$ and $2 \mathrm{~b}$. Table $2 \mathrm{a}$ shows that ethnic minorities showed significantly higher attitudes towards cultural diversity promotion $(r=.19, p<.001)$ and significantly higher intentions $(r$ $=.27, p<.001)$ than ethnic majorities. Significant correlations were also found for sex and age, but further inspection of the data showed that this was explained by job position (i.e., management position or not). The existence of a cultural diversity policy in the organization was positively related to attitude $(r=.29, p<.001)$, subjective norm $(r=.45, p<.001)$, intentions $(r$ $=.20, p<.001)$, and behavior $(r=.31, p<.001)$. Table $2 \mathrm{~b}$ shows the means and inter correlations among study variables for employees and managers separately.

Because self-selection could have influenced the results (i.e., those with a positive attitude towards cultural diversity may have been more likely to participate again at T2), we checked for possible differences in sample characteristics between T1 $(N=660)$ and T2 $(n=$ 172). Means were compared of the main study variables (attitude, social norm, PBC, intentions) and demographic characteristics (sex, age, ethnicity) of the group that participated only once $(\mathrm{T} 1 ; n=498)$ and the group that also participated in the follow-up study (T1 and T2; $n=172$ ). No significant differences were found for the TPB variables between the participants that 
DIVERSITY SUPPORT AT WORK

participated only at $\mathrm{T} 1$ and those who participated at $\mathrm{T} 1$ and $\mathrm{T} 2$. Thus, no significant differences existed for attitude $(M$ attitude-T1-only $=3.83, S D=0.91 ; M$ attitude-T1-and-T2 $=3.84, S D=0.87, t=$ $-.22, p=.83)$, social norm $(M$ social norm-T1-only $=3.16, S D=1.04 ; M$ social norm-T1-and-T2 $=3.04$, $S D=1.01, t=1.31, p=.19), \mathrm{PBC}(M$ PBC-T1-only $=2.79, S D=1.42 ; M$ PBC-T1-and-T2 $=2.58, S D$ $=1.28, t=1.72, p=.09)$ and intentions $(M$ intention-T1-only $=3.43, S D=1.05 ; M$ intention-T1-and$\mathrm{T} 2=3.31, S D=1.06, t=1.30, p=.20)$. Significant differences were found for age $(M$ age-T1-only $=36.70, S D=11.94 ; M$ age-T1-and-T2 $=41.13, S D=11.18)$ and ethnicity $(M$ ethnicity-T1-only $=$ $0.25, S D=0.44 ; M$ ethnicity-T1-and-T2 $=0.17, S D=0.38)$. The group that participated at $\mathrm{T} 1$ and T2 was somewhat older and included fewer ethnic minorities compared to those who participated at T1 only. Therefore, these two variables were controlled for in the analyses.

\section{Preliminary analyses}

Before testing our hypotheses, we tested both the distinctiveness of our measures as well as the full TPB model using structural equation modelling in AMOS v. 20 (Byrne, 2010). Full information maximum likelihood estimation method was used to deal with missing data (Graham \& Coffman, 2012).

First, we conducted a confirmatory factor analysis (CFA) using maximum likelihood on all study measures at T1 (i.e., attitude, social norm, PBC and intentions) to test the factorial structure of the TPB model. Results showed a good fit to the data for the four factors of the TPB model, $\chi^{2}(48, N=670)=161.77, p<.001, \mathrm{CFI}=.98, \mathrm{TLI}=.97, \mathrm{RMSEA}=.06$. To detect possible method bias, we additionally tested a model in which all T1 indicators loaded on a single, common factor (Podsakoff, MacKenzie, \& Podsakoff, 2012). This analysis implies that if a single factor fits the data, method variance is largely responsible for the covariation among the T1 data. A single factor model, however, did not fit the data well $\left(\chi^{2}(54, N=670)=1975.17, p\right.$ 
DIVERSITY SUPPORT AT WORK

$<.001, \mathrm{CFI}=.64, \mathrm{TLI}=.47, \mathrm{RMSEA}=.23)$. Instead, the four factor model (with attitude, social norm, PBC and intentions) provided a much better fit than the single factor model, indicating that the respondents distinguished between the four constructs $\left(\Delta \chi^{2}(6, N=670)=1813.40, p<\right.$ .001). Because of the highly significant correlation between attitudes and intention $(r=.75, p<$ $.001)$, an extra model was tested in which the attitude and intention items loaded on the same latent factor. The fit of this model, however, was poorer $\left(\chi^{2}(56, N=670)=838.18, p<.001\right.$, $\mathrm{CFI}=.90, \mathrm{TLI}=.88, \mathrm{RMSEA}=.14)$ than the four factor model $\left(\chi^{2}(48, N=670)=161.77, p<\right.$ $\left..001, \mathrm{CFI}=.98, \mathrm{TLI}=.97, \mathrm{RMSEA}=.06 ; \Delta \chi^{2}(8, N=670)=676.41, p<.001\right)$. Hence , because empirical evidence supported the four factorial model of the TPB at T1, this model was used for further analyses.

Subsequently, we conducted a path analysis using CFA on the full TPB model, including the data on behavior at T2. Results showed a good fit: $\chi^{2}(164)=572.89, p<.001, \mathrm{CFI}=0.97$, $\mathrm{TLI}=0.95, \mathrm{RMSEA}=0.04$. An additional CFA was performed in which sex, age, race and cultural diversity policy were included as control variables because of the significant correlations. The results for this model were fairly similar compared to the model without controls: $\chi^{2}(114)=368.40, p<.001, \mathrm{CFI}=0.95, \mathrm{TLI}=0.92, \mathrm{RMSEA}=.06$. The standardized estimates for the model in which controls were included were similar to the model without controls, but the estimates for the covariates were smaller in the model using controls. The standardized estimates resulting from the CFA in which controls were included are represented in Figure 1.

Finally, a multigroup analysis was performed to study the factorial invariance of the TPB variables in predicting intentions for managers and employees (configural invariance: $\chi^{2}(96)=$ 432.44, $p=.00, \mathrm{CFI}=0.94, \mathrm{TLI}=0.94, \mathrm{RMSEA}=0.07$; metric invariance: $\chi^{2}(111)=449.96, p$ 
$\left.<.001, \mathrm{CFI}=0.94, \mathrm{TLI}=0.93, \mathrm{RMSEA}=0.07 ; \Delta \chi^{2}(15)=17.53, \mathrm{p}=.29\right)$. Furthermore, no significant differences at the path level were found in regression weights for both groups (Table 3), thereby establishing the invariance of the model across employees and managers.

\section{Hypothesis testing}

The first hypothesis stated that attitudes towards cultural diversity promotion, assessment of the subjective norm about cultural diversity issues, and perceived behavioral control related to cultural diversity promotion would be positively related to intentions to engage in cultural diversity promotion activities at their work. The CFA rendered support for our first hypothesis $\left(\chi^{2}(48, N=670)=161.77, p<.001, \mathrm{CFI}=.98, \mathrm{TLI}=.97, \mathrm{RMSEA}=.06\right)$. When looking at the regression weights, only attitude and $\mathrm{PBC}$ were significant in predicting intentions (see Figure 1).

Hypothesis 2 further stated that managers would perceive higher behavioral control related to cultural diversity promotion and stronger intention to engage in cultural diversity promotion activities at their work than employees. Differences in latent means were found between managers and employees on PBC, but not on intentions, thereby partly supporting Hypothesis 2 $(\mathrm{PBC}: M$ manager $=3.27(S D=1.32), M$ employee $=2.09(S D=1.15)$, C.R. $=2.21, p=.03$; Intention: $M$ manager $=3.50(S D=1.09), M$ employee $=3.31(S D=1.02)$, C.R. $=0.85, p=.40)$.

Hypothesis 3 stated that intention to engage in cultural diversity promotion activities at work and perceived behavioral control in cultural diversity promotion will be positively related to actual behavior. In line with Hypothesis 3, intentions in combination with PBC predicted behavior (Hypothesis 3; Figure 1). Yet, a Repeated Measures Ancova showed that the observed means for behavior were significantly lower than for intentions (Table 2a, $M$ intention $=3.31, S D$ $=1.06 ; M$ behavior $\left.=1.95, S D=0.97 ; F(171)=335.38, p<.001, \eta^{2}=.66\right)$. 
DIVERSITY SUPPORT AT WORK

Finally, Hypothesis 4 stated that managers would engage in more cultural diversity promotion activities. The results supported that managers engaged in more cultural diversity promotion activities at their work compared to employees (Behavior: $M$ manager $=2.16(S D=$ 1.14), $M$ employee $=1.73(S D=0.69)$, C.R. $=-3.11, p<.00)$.

\section{Discussion}

Following cultural diversity policies and actually showing diversity promotion related behaviors is a deliberate, conscious action that does not necessarily come naturally. A better understanding of what gets people to actually act based on their psychological support is much needed. Using a two-wave longitudinal design, this study showed support for the applicability of the theory of planned behavior in predicting individuals' intentions and behavior to promote cultural diversity management activities at work. When looking at the regression weights, only attitude and perceived behavioral control (PBC) were significant in predicting intentions. The strongest driver of intentions, for both managers and employees, was attitude towards cultural diversity management promotion. Attitudes are known to be relatively stable and difficult to change (Harrison et al., 2006). Organizations trying to build a cultural inclusive organization may want to focus on attitude, especially when selecting managers.

Intentions, in combination with PBC predicted actual cultural diversity management promotion behavior. PBC may be influenced more easily compared to attitudes, for instance through awareness training or training in cross-cultural competencies (i.e., thereby addressing the self-efficacy part of $\mathrm{PBC}$ ), or appointing a diversity manager to whom employees and managers can turn when they want to advocate cultural diversity initiatives (i.e., thereby addressing the controllability part of PBC). Further, managers, on average, did score significantly higher on PBC and diversity supportive behavior than employees. The findings partly support the idea that 
managers engaged in more cultural diversity management promotion activities at work than employees. In line with the TPB model we found a direct relation between PBC and behavior. Although this relation between PBC and behavior was similar for employees and managers, the higher latent means in PBC for managers may explain the difference in behavior. Managers' intentions, however, were not significantly higher compared to those of employees. The difference in mean intention scores between managers and employees were in the expected direction though, albeit non-significant when using latent mean analysis. Taken together, it seems that managers do not have higher intentions, but that their perceived opportunity to support diversity $(\mathrm{PBC})$ is higher than that of employees, which may explain why managers engage in more diversity supportive behavior than employees. For organizations aiming to increase the effectiveness of their cultural diversity management practices, this means that increasing $\mathrm{PBC}$ can be beneficial due to the direct relation with behavior. The means for behavior were significantly lower than for intentions for both managers and employees. Previous research using the theory of planned behavior has shown that intentions do not always predict behaviors in particular contexts (Davies, Foxall, \& Pallister, 2002). Yet, in the current study, intentions did predict reported behavior after six months, but the means for behavior were lower compared to intentions. A possible explanation for this gap may be the types of behavior we asked about, which were cultural diversity management promotion activities in the last six months. Perhaps participants did not have the opportunity to engage in promotion behavior as envisioned by themselves (e.g., influence the cultural diversity policy), especially when the workforce in the organization may have remained stable (i.e., no changes in team composition or new hires/promotions). Building an inclusive organization requires a long-term focus, especially when looking at the slow rate with which ethnic and other minorities are considered for and 
promoted into higher management positions (Benton et al., 2014; O’Brien, Scheffer, Van Nes, \& Van der Lee, 2015). Hence, despite individual intentions, actual cultural diversity management promotion behaviors may lag behind because of this.

Note that subjective norm did not predict intentions in our model. The results from the correlational table did show, however, that the existence of a cultural diversity policy was positively related to a higher reported subjective norm. Indeed, an exploratory survey item showed that among the main perceived obstacles to introduce or implement a cultural diversity policy in one's own organization were a lack of sense of urgency in the organization (51.9\%) and the organizational culture $(37.5 \%)$. The social norm may partly become explicit in the existence or absence of a diversity policy within the organization. Because of the support found for the theory of planned behavior to predict actual behavior in the current study, it can be concluded here that attitudes and PBC are more influential as antecedents of this behavior compared to social norm.

\section{Strengths, Limitations, and Implications}

Although recently several theoretical, multi-level models have been published on diversity management endorsement and outcomes, empirical evidence on the psychological underpinnings of cultural diversity support at work is still scarce, especially empirical evidence outside the lab. The study described here was done among actual employees and managers and therefore provides solid, empirical ground for further theory building on cultural diversity promotion behaviors as well as for the development of practical guidelines for effective cultural diversity policy implementation at work. Of course, as with all research, this study was not without limitations. The survey relied on single-source self-report data and thus only selfreported predictors and behavior could be assessed. First, although caution is warranted when 
DIVERSITY SUPPORT AT WORK

interpreting these single-source self-report data, no evidence for potential common method variance was found in our dataset (Podsakoff \& Organ, 1986). Second, although a good fit of the TPB-model to the data was found, self-reported behavior may still be different from one's actual behavior. Specifically, due to consistency motives and/or social desirability, actual behavior may be even lower than the self-reported behavior that was used in this study for analysis.

This study focused on individual determinants of promotion of cultural diversity at work. As mentioned, attitude was the strongest driver of reported intentions and behavior in this study. Future research may focus on ways to influence attitudes towards cultural diversity at work, especially among employees in influential decision making positions. One suggestion for further research may be to focus on morality. It has been argued that morality is one of the most important regulators of behavior (Does, Derks, \& Ellemers, 2012). For instance, Does et al. (2012) conducted studies on the functionality of morality to shape intergroup attitudes on social equality issues. In a series of lab experiments they showed that presenting social equality between ethnic groups in terms of moral ideals, such as equal treatment, rather than as moral obligations to prevent discrimination resulted in more support for affirmative action among White ethnic majority participants. Does et al. (2012) used a cross-sectional, between-subjects design and no pre-tests, thus it remains unknown whether there was an actual, lasting change in attitudes. Future research may therefore focus on the influence of framing cultural diversity management (i.e., as a moral ideal or a moral obligation) on attitude change within individuals over a longer period of time. Another suggestion for future research on attitude change is on influencing self-regulatory states of individuals when thinking about their behaviors. Ellemers, Scheepers, and Popa (2010) showed in a lab study that promotion-oriented emotions (e.g., enthusiasm) predicted individual support for affirmative action, but only when the in-group to 
which the participant belonged was seen to benefit from it. Prevention-oriented emotions (e.g., feeling upset) only predicted support when the in-group was portrayed as standing to lose from affirmative action. Future research may test these findings and elaborate on this in a real-life work context.

Although behavior was predicted by intentions in the study presented here, the gap in mean scores between intentions and actual behavior is interesting and suggests investigating an extended model. Future research may include other psychological constructs which are less cognitive in nature compared to the TPB variables, such as diversity beliefs, prejudice and egalitarianism to better understand the causes of employees' diversity-related behaviors. Furthermore, the size of the organization, the diversity make-up of the organization (i.e., percentage of ethnic minority employees and managers) and the existence of a cultural diversity policy in the organization can be included when using a multi-level approach, including individual and organizational level constructs. Results indeed showed that a cultural diversity policy at the organizational level is positively related to intentions and behavior to promote cultural diversity management at work. Finally, our research showed support for the applicability of TPB in a European context, namely the Netherlands, when investigating cultural diversity related intentions and behavior. To the best of our knowledge, this has never been investigated before. Future research may expand to other Western and non-Western countries to assess the generalizability of our findings, not only regarding cultural diversity but also regarding race and other subgroups at work (e.g., based on age and gender).

\section{Conclusion}

To conclude, this study found empirical support for the theory of planned behavior across a variety of actual organizations and job positions, thereby improving our 
understanding of behavioral drivers of managers and employees towards cultural diversity management promotion at work. With an increasingly diverse workforce, more understanding of psychological reactions to cultural diversity measures at work is necessary and might stimulate further research in this direction.

\section{References}

Ajzen, I. (1991). The theory of planned behavior. Organizational Behavior and Human Decision Processes 50, 179-211. doi: 10.1016/0749-5978(91)90020-T

Ajzen, I. (2002). Perceived behavioral control, self-efficacy, locus of control, and the theory of planned behavior. Journal of Applied Social Psychology, 32, 665-683. doi: 10.1111/j.15591816.2002.tb00236.x

Ajzen, I., \& Fishbein, M. (1975). Belief attitude, intention, and behavior: An introduction to theory and research. Massachusetts: Addison-Wesley.

Avery, D. R. (2011). Support for diversity in organizations: A theoretical exploration of its origins and offshoots. Organizational Psychology Review, 1, 239-256. doi: $10.1177 / 2041386611402115$

Avery, D. R., McKay, P. F., Wilson, D. C., \& Tonidandel, S. (2007). Unequal attendance: The relationships between race, organizational diversity cues, and absenteeism. Personnel Psychology, 60, 875-902. doi:10.1111/j.1744-6570.2007.00094.x

Bandura, A. (1982). Self-efficacy mechanism in human agency. American Psychologist, 37, 122147. doi:10.1037/0003-066X.37.2.122

Bell, M. P., Harrison, D. A., \& McLaughlin, M. E. (2000). Forming, changing, and acting on attitude toward affirmative action programs in employment: A theory-driven approach. Journal of Applied Psychology 85, 784-798. doi: 10.1037/0021-9010.85.5.784 
DIVERSITY SUPPORT AT WORK

Benton, M., Fratzke, S., \& Sumption, M. (2014). Moving up or standing still? Access to middleskilled work for newly arrived migrants in the European Union. Geneva, Switzerland: ILO. doi: http://hdl.voced.edu.au/10707/342012

Brief, A. P., Dietz, J., Cohen, R. R., Pugh, S. D., \& Vaslow, J. B. (2000). Just doing business: Modern racism and obedience to authority as explanations for employment discrimination. Organizational Behavior and Human Decision Processes, 81, 72-97. doi: 10.1006/obhd.1999.2867

Byrne, B.M. (2010). Structural Equation Modeling with AMOS. New York, NY: Routledge Taylor \& Francis Group.

Central Bureau of Statistics (CBS; 2012). Bevolking naar herkomstgroepering en generatie [Population’s ethnic background and generation]. Retrieved 20 March 2013 from: http//www.cbs.nl.

Cordano, M., \& Frieze, I. H. (2000). Pollution reduction preferences of U.S. environmental managers: Applying Ajzen's theory of planned behavior. Academy of Management Journal, 43, 627-641. doi: 10.2307/1556358

Crosby, F., Iyer, A., Clayton, S., \& Downing, D. (2003). Affirmative action - psychological data and the policy debates. American Psychologist, 58, 93-115. doi: 10.1037/0003-066X.58.2.93

Davies, J., Foxall, G.R., \& Pallister, J. (2002). Beyond the intention - behaviour mythology: An integrated model of recycling. Marketing Theory, 2, 29-113. doi: $10.1177 / 1470593102002001645$

Derous, E., Ryan, A. M., \& Nguyen, H. D. (2012). Multiple categorization in resume screening: Examining effects on hiring discrimination against Arab applicants in field and lab settings. Journal of Organizational Behavior, 33, 544-570. doi:10.1002/job.769 
DIVERSITY SUPPORT AT WORK

Does, S., Derks, B., \& Ellemers, N. (2011). Thou shalt not discriminate: How emphasizing moral ideals rather than obligations increases Whites' support for social equality. Journal of Experimental Social Psychology, 47, 562-571. doi:10.1016/j.jesp.2010.12.024

Dolfing, M. \& van Tubergen, F. (2005). Bensaïda of Veenstra? Een experimenteel onderzoek naar discriminatie van Marokkanen in Nederland. [Bensaïda or Veenstra? An experimental study on discrimination of Moroccans in the Netherlands]. Sociologie, 1, 407-422. doi:10.1347/sogi.2005.1.4.407

Ellemers, N., Scheepers, D., \& Popa, A. M. (2010). Something to gain or something to lose? Affirmative action and regulatory focus emotions. Group Processes \& Intergroup Relations, 13, 201-213. doi:10.1177/1368430209343296

Elliott, R. J. R., \& Lindley, J. K. (2008). Immigrant wage differentials, ethnicity and occupational segregation. Journal of the Royal Statistical Society Series A-Statistics in Society, 171, 645671. doi: 10.1111/j.1467-985X.2007.00535.x

European Commission (2009). International perspectives on positive action measures. A comparative analysis in the European Union, Canada, The United States and South Africa. Luxembourg: Office for official publications of the European Communities. Retrieved 28 March 2013 from: https://publications.europa.eu/en/home

European Union (2000). Racial equality directive (2000/43/EC). Luxembourg: Office for official publications of the European Communities. Retrieved 28 March 2013 from: https://publications.europa.eu/en/home

European Union (2009). Developing anti-Discrimination law in Europe. The 27 EU member states compared. Luxembourg: Office for official publications of the European Communities. Retrieved 30 March 2013 from: https://publications.europa.eu/en/home 
DIVERSITY SUPPORT AT WORK

Forum (2012). Allochtonen op de arbeidsmarkt le kwartaal 2012 - $10^{e}$ monitor. [Labor market position of ethnic minorities first term 2012]. Utrecht, the Netherlands: Forum Institute for Multicultural Affairs.

Greaves, M., Zibarras, L. D., \& Stride, C. (2013). Using the theory of planned behavior to explore environmental behavioral intentions in the workplace. Journal of Environmental Psychology, 34, 109-120. doi: 10.1016/j.jenvp.2013.02.003

Graham, J. W., \& Coffman, D. L. (2012). Structural equation modelling with missing data. In: R.H. Hoyle (Ed.). Handbook of Structural Equation Modeling. NY: The Guilford Press.

Groeneveld, S., \& Verbeek, S. (2012). Diversity policies in public and private sector organizations: An empirical comparison of incidence and effectiveness. Review of Public Personnel Administration, 32(4), 353-381. doi:10.1177/0734371X11421497

Guillaume, Y. R. F., Dawson, J. F., Priola, V., Sacramento, C. A., Woods, S. A., Higson, H. E., . . West, M. A. (2014). Managing diversity in organizations: An integrative model and agenda for future research. European Journal of Work and Organizational Psychology, 23(5), 783802. doi:10.1080/1359432X.2013.805485

Haley, H., \& Sidanius, J. (2006). The positive and negative framing of affirmative action: A group dominance perspective. Personality and Social Psychology Bulletin, 32, 656668. doi: $10.1177 / 0146167205283442$

Harrison, D. A., Kravitz, D. A., Mayer, D. M., Leslie, L. M., \& Lev-Arey, D. (2006). Understanding attitudes toward affirmative action programs in employment: Summary and meta-analysis of 35 years of research. Journal of Applied Psychology, 91, 1013-1036. doi: 10.1037/00219010.91 .5 .1013 
Hollifield, J. F., Martin, P. L., \& Orrenius, P. M. (2014). Controlling immigration: A global perspective. Stanford: Stanford University Press.

Hoque, K., \& Noon, M. (2004). Equal opportunities policy and practice in Britain: Evaluating the 'empty shell' hypothesis. Work Employment and Society, 18, 481-506. doi:10.1177/0950017004045547

Jansen, W. S., Otten, S., \& van der Zee, K. I. (2015). Being part of diversity: The effects of an allinclusive multicultural diversity approach on majority members' perceived inclusion and support for organizational diversity efforts. Group Processes \& Intergroup Relations, 18, 817-832. doi:10.1177/1368430214566892

Jimmieson, N. L., Peach, M., \& White, K. M. (2008). Utilizing the theory of planned behavior to inform change management: An investigation of employee intentions to support organizational change. The Journal of Applied Behavioral Science, doi: $10.1177 / 0021886307312773$

Kalev, A., Dobbin, F., \& Kelly, E. (2006). Best practices or best guesses? Assessing the efficacy of corporate affirmative action and diversity policies. American Sociological Review, 71, 589617. doi: $10.1177 / 000312240607100404$

Kellough, J. E., \& Naff, K. C. (2004). Responding to a wake-up call - an examination of federal agency diversity management programs. Administration \& Society, 36, 62-90. doi: $10.1177 / 0095399703257269$

Kelly, E., \& Dobbin, F. (1998). How affirmative action became diversity management. American Behavioral Scientist, 41, 960-984. doi: 10.1177/0002764298041007008 
DIVERSITY SUPPORT AT WORK

Kossek, E. E., \& Pichler, S. (2007). EEO and the Management of Diversity. In: P. Boxall, J. Purcell, \& P. Wright (Eds). The Oxford Handbook of Human Resource Management, 251272. Oxford; New York: Oxford University Press.

Kravitz, D. A., Harrison, D. A., Turner, M. E., Levine, E. L., Chaves, W., \& Brannick, M. T. (1997). Affirmative action: A review of psychological and behavioral research. Bowling Green, OH: Society for Industrial and Organizational Psychology.

Linnehan, F., Chrabot-Mason, D., \& Konrad, A. M. (2006). Diversity attitudes and norms: The role of ethnic identity and relational demography. Journal of Organizational Behavior, 27, 419-442. doi: 10.1002/job.382

Linnehan, F., Konrad, A. M., Reitman, F., Greenhalgh, A., \& London, M. (2003). Behavioral goals for a diverse organization: The effects of attitudes, social norms, and racial identity for Asian Americans and Whites. Journal of Applied Social Psychology, 33, 1331-1359. doi: 10.1111/j.1559-1816.2003.tb01952.x

McCabe, P. C., \& Rubinson, F. (2008). Committing to social justice: The behavioral intention of school psychology and education trainees to advocate for lesbian, gay, bisexual, and transgendered youth. School Psychology Review, 37, 469-486. Retrieved 28 March 2013 from: http://psycnet.apa.org/psycinfo/2009-00707-002

McKay, P. F., Avery, D. R., \& Morris, M. A. (2009). A tale of two climates: Diversity climate from subordinates' and managers' perspectives and their role in store unit sales performance. Personnel Psychology, 62, 767-791. doi:10.1111/j.1744-6570.2009.01157.x

Nacoste, R. W., \& Hummels, B. (1994). Affirmative action and the behavior of decision makers. Journal of Applied Social Psychology, 24, 595-613. doi: 10.1111/j.15591816.1994.tb00602.x 
DIVERSITY SUPPORT AT WORK

Nijenhuis, J., te, de Jong, M., Evers, A., \& van der Flier, H. (2004). Are cognitive differences between immigrant and majority groups diminishing? European Journal of Personality, 18, 405-434. doi: 10.1002/per.511

O’Brien, K.R., Scheffer, M., van Nes, E.H., \& van der Lee, R. (2015). How to Break the Cycle of Low Workforce Diversity: A Model for Change. PLoS ONE, 10, e0133208. doi:

\subsection{1/journal.pone.0133208}

Olsen, J. E., \& Martins, L. L. (2012). Understanding organizational diversity management programs: A theoretical framework and directions for future research. Journal of Organizational Behavior, 33, 1168-1187. doi:10.1002/job.1792

Organization for Economic Cooperation and Development (2013). Migration and unemployment. OECD Factbook 2013: Economic, Environmental and Social Statistics. Paris, France: OECD Publishing. Retrieved 2 April 2013 from: http://dx.doi.org/10.1787/factbook-2013-9en

Plaut, V. C., Garnett, F. G., Buffardi, L. E., \& Sanchez-Burks, J. (2011). "What about me?" Perceptions of exclusion and Whites' reactions to multiculturalism. Journal of Personality and Social Psychology, 101, 337-353. doi:10.1037/a0022832

Plaut, V. C., Thomas, K. M., \& Goren, M. J. (2009). Is multiculturalism or color blindness better for minorities?. Psychological Science, 20, 444-446. doi: 10.1111/j.14679280.2009.02318.x

Podsakoff, P. M., \& Organ, D. W. (1986). Self-reports in organizational research - problems and prospects. Journal of Management, 12, 531-544. doi:10.1177/014920638601200408

Schreurs, B., Derous, E., Van Hooft, E. A. J., Proost, K., \& De Witte, K. (2009). Predicting applicants' job pursuit behavior from their selection expectations: The mediating role of the 
theory of planned behavior. Journal of Organizational Behavior, 30, 761-783. doi:10.1002/job.570

Shore, L. M., Randel, A. E., Chung, B. G., Dean, M. A., Ehrhart, K. H., \& Singh, G. (2011). Inclusion and diversity in work groups: A review and model for future research. Journal of Management, 37(4), 1262-1289. doi:10.1177/0149206310385943

Sussmuth, R. (2007). Ethnic minorities in the labour market. An urgent call for better social inclusion. Brussels, Belgium: European Commission.

Thomas, R. R. (1990). From affirmative action to affirming diversity. Harvard Business Review, 68, 107-117.

Trafimow, D., Sheeran, P., Conner, M., \& Finlay, K. (2002). Evidence that perceived behavioural control is a multidimensional construct: Perceived control and perceived difficulty. British Journal of Social Psychology, 41, 101-121. doi:10.1348/014466602165081

Vervoort, M., \& Dagevos, J. (2011). The social integration of ethnic minorities: An explanation of the trend in ethnic minorities' social contacts with natives in the Netherlands, 1998-2006. Journal of Ethnic and Migration Studies, 37, 619-635.

doi:10.1080/1369183X.2011.545279

Walsh, A. M., Hamilton, K., White, K. M., \& Hyde, M. K. (2015). Use of online health information to manage children's health care: A prospective study investigating parental decisions. BMC Health Services Research, 15, 1-10. doi:10.1186/s12913-015-0793-4

Yang, Y., \& Konrad, A. M. (2011). Understanding diversity management practices: Implications of institutional theory and resource-based theory. Group \& Organization Management, 36, 6-38. doi:10.1177/1059601110390997 


\section{Appendix A - TPB items}

\section{Attitude}

I think it is useful for our organization to have a cultural diversity policy.

I like the idea that our company has a cultural diversity policy.

I think it is good to have a cultural diversity policy in our organization.

\section{Subjective norm}

Important people in my organization think that cultural diversity policy is necessary for our organization.

Important people in my organization think that there should be more attention paid to the position of ethnic minorities in our organization.

Important people in my organization think that our organization should promote cultural diversity.

\section{$P B C$}

My position gives me enough power to implement cultural diversity increasing activities.

I can influence the recruitment and retention of ethnic minorities.

I have a saying about having or extending the cultural diversity policy.

\section{Intention}

I want to actively influence the cultural diversity policy in my organization.

I want to take more responsibilities to improve position of ethnic minorities in my organization.

I want to make a stand for a better cultural diversity policy in our organization.

\section{Behavior}

In the past six months I have actively influenced cultural diversity policy in my organization.

In the past six months I have actively influenced the cultural diversity policy in our organization.

In the past six months I have taken up more responsibility to improve the position of ethnic minorities in our organization. 